\title{
Microstructure Evolution in a Fast and Ultrafast Sintered Non-Equiatomic Al/Cu HEA
}

\author{
Eduardo Reverte ${ }^{1, *(\mathbb{D}}$, Juan Cornide ${ }^{1}$, Miguel A. Lagos $^{2}$, Mónica Campos $\left.{ }^{1} \mathbb{(}\right)$ and Paula Alvaredo ${ }^{1} \mathbb{C}$ \\ 1 Department of Materials Science and Engineering, IAAB, Universidad Carlos III de Madrid, \\ Avda. Universidad 30, 28911 Leganés, Spain; jcornide@ing.uc3m.es (J.C.); campos@ing.uc3m.es (M.C.); \\ palvared@ing.uc3m.es (P.A.) \\ 2 TECNALIA, Basque Research and Technology Alliance (BRTA), Mikeletegi Pasealekua 2, \\ 20009 Donostia-San Sebastián, Spain; miguelangellagosgomez@gmail.com \\ * Correspondence: ereverte@ing.uc3m.es
}

check for updates

Citation: Reverte, E.; Cornide, J.; Lagos, M.A.; Campos, M.;

Alvaredo, P. Microstructure Evolution in a Fast and Ultrafast Sintered Non-Equiatomic $\mathrm{Al} / \mathrm{Cu}$ HEA. Metals 2021, 11, 848. https://doi.org/ $10.3390 /$ met11060848

Academic Editor: Ilaria Cristofolini

Received: 16 April 2021

Accepted: 18 May 2021

Published: 21 May 2021

Publisher's Note: MDPI stays neutral with regard to jurisdictional claims in published maps and institutional affiliations.

Copyright: (c) 2021 by the authors. Licensee MDPI, Basel, Switzerland. This article is an open access article distributed under the terms and conditions of the Creative Commons Attribution (CC BY) license (https:// creativecommons.org/licenses/by/ $4.0 /)$.

\begin{abstract}
One of the attractive characteristics of high entropy alloys (HEAs) is the ability to tailor their composition to obtain specific microstructures and properties by adjusting the stoichiometry to obtain a body-centered cubic (BCC) or face-centered cubic (FCC) structure. Thus, in this work, the target composition of an alloy of the $\mathrm{FeCrCoNi}$ family has been modified by adjusting the $\mathrm{Al} / \mathrm{Cu}$ ratio in order to obtain a $\mathrm{BCC}$ crystalline structure. However, processing conditions always play a key role in the final microstructure and, therefore, in this work, the microstructure evolution of $\mathrm{FeCrCoNiAl}_{1.8} \mathrm{Cu}_{0.5}$ HEA sintered by different powder metallurgy (PM) techniques has been investigated. The techniques used range from the conventional PM sintering route, that uses high heating rates and sintering times, going through a fast sintering technique such as spark plasma sintering (SPS) to the novel and promising ultrafast sintering technique electrical resistance sintering (ERS). Results show that the increase in the processing time favours the separation of phases and the segregation of elements, which is reflected in a substantial change in the hardness of the alloy. In conclusion, the ERS technique is presented as a very promising consolidation technique for HEA.
\end{abstract}

Keywords: high entropy alloys; microstructure; ordered body-centered cubic (BCC/B2); $\mathrm{Cr}-\mathrm{Co}-$ $\mathrm{Fe}-\mathrm{Ni}-\mathrm{Al}-\mathrm{Cu}$; powder metallurgy; spark plasma sintering; electrical resistance sintering; ultrafast sintering technique

\section{Introduction}

One of the most interesting characteristics of HEAs is that they can form a simple solid solution with high lattice distortion and a low diffusion coefficient which is reflected in their characteristic mechanical properties [1,2].

The process by which these multicomponent alloys form solid solutions is still to be solved as many empirical and theoretical predictions try to predict the dominant factors controlling formation. From the thermodynamic approach with the mixing of entropy and enthalpy to the size factor effects related to the lattice distortion or differences in atomic radius of the elements to, finally, the Hume-Ruthery rules such as the electronegativity mismatch or the electron per atom (e/a), these criteria describe the formation of solid solutions in the complex high entropy alloys they can help to understand some individual aspects [3-5].

The characteristics of the solid solution give rise to alloys with high stability, hardness, and strength, also at high temperatures, which has aroused the interest of the scientific community in showing potential applications as catalysts [6], aerospace materials [7], and nuclear materials [8] apart from metallurgical applications.

Not all HEA compositions result in the formation of a solid solution. There are several studies which state empirical rules based on the characteristics of the involved elements that predict phase formation with high reliability [4,9-11]. However, to be successful in 
achieving the formation of the desired phase and, therefore, in the expected properties, it is necessary to know how the conditions applied during the processing of the alloy affect the final microstructure.

There are an increasing number of publications devoted to the study of the influence of the processing routes in the final properties of HEAs. Most of them rely on the casting production routes, such as induction or arc melting. However, PM technologies show great possibilities as a method to produce these types of alloys. Most of the studies of the PM routes show that they follow a first stage of mechanical alloying of elemental (or prealloyed) powders to obtain the desired composition of the alloy [12]. Secondly, the powders are usually consolidated via rapid sintering methods such as spark plasma sintering (SPS) to achieve high densifications [13]. Nevertheless, there is a lack of information about the role of high heating and cooling rates as well as processing time in the HEA's phase formation.

This work relies on the development of BCC structures in a non-equiatomic $\mathrm{CoCrFeNiAl}_{1.8} \mathrm{Cu}_{0.5} \mathrm{HEA}$ suitable for moderate high temperature applications with a relative low density and enough hardness below the refractory HEA type. Several authors studied the advantages of BCC structures over the FCC type in severe conditions as this phase show high values of harness and mechanical strength at elevated temperatures [14]. Among the most studied HEAs, the equiatomic $\mathrm{CrCoFeNiAlCu}$ alloy is widely studied [15-19]. With the addition of aluminium, hardness increase by the dissolution of aluminium atoms in the BCC and FCC phases while decreasing the overall density of the alloy has been already proven. Moreover, precipitation of nano-sized AlNi (B2) phase could possibly increase these values [20,21]. Furthermore, copper segregation in grain boundaries has been observed, promoting a limitation in the performance at higher temperatures. To overcome these issues and based on the empirical phase rules published in the literature [4,9-11], aluminium and copper content was modified, aluminium increased to 1.8 and copper reduction until 0.5 to stabilise the BCC structure and improve the mechanical behaviour at temperature approximately of $600{ }^{\circ} \mathrm{C}$.

However, the final phase formation does not depend solely on the composition, but the parameters used during the processing also play a key role [22]. For this reason, different PM sintering techniques have been chosen in which different sintering times and heating and cooling rates are used.

The sintering techniques used are conventional pressing and sintering (P\&S), spark plasma sintering (SPS), and electrical resistance sintering (ERS). These last two techniques are within the electric current assisted sintering (ECAS) techniques [23]. The main difference between them is the processing time and that in conventional ECAS processes such as SPS (a fast sintering technique), low current densities and voltage are applied (typically $<10 \mathrm{~V}$ and $1 \mathrm{kA} / \mathrm{cm}^{2}$ ) [24]. With these conditions, processing time is in the range of minutes and, for that reason, a controlled atmosphere is needed. However, in ultrafast processes such as ERS [25-27] higher current densities are applied (typically $>5 \mathrm{kA} / \mathrm{cm}^{2}$ ), and the processing time is a few seconds. The short cycle time enables processing in air without any protective atmosphere [24].

ERS has been applied to consolidate metallic materials with good conductivity such as iron [28] and titanium [25], but is also a good technique to consolidate compound materials such as cemented carbides with low conductivity thanks to the high current applied, and the results showed lower grain growth to be a potential way to consolidate these type of metal-ceramic materials [29]. In the case of HEA, not only is the limitation in grain growth provided by an ultrafast sintering technique of interest, but also that it can avoid the segregation of elements and the formation of undesirable phases.

The formal use of HEA families is still on hold for industrial applications due to the lacking research into the properties these alloys [30]. Nonetheless, it is also necessary to evaluate viable processing routes. The three processing methods of study allow the process of metal and ceramic components nowadays with some limitation to some extent, mainly on the specialised ECAS techniques [23], whereas to comply with the size/shape effects of about 100-300 mm diameter, for the larger geometries, substantial know-how is 
needed in management to obtain dense and homogeneous sintered materials [31]. These disadvantages with such fast techniques are being overcome as new technology advances and industrial patents emerges [31], though slowly. Regarding the P\&S sintering route, this process is simple and economical as it is still being used in the mass production industries at a cost of performance [30].

The segregation of elements in HEA is shown as one of the main drawbacks and has been observed in various works and compositions [32,33]. In general, the strategies followed to avoid segregation have focused on the modification of the composition as the development of eutectic alloys [34,35], while in this work, it is intended to use a strategy focused on the processing and not on the modification of the composition. The results obtained in this work have made it possible to understand the evolution of the phase formation and the microstructure with the processing time as well as its reflection in the final properties of the sample.

\section{Materials and Methods}

The HEA composition follows the empirical rules of phase formation published in the literature with the aim to obtain a simple BCC solid solution, resulting in $\mathrm{FeCrCoNiAl}_{1.8} \mathrm{Cu}_{0.5}$. The nominal composition is shown in Table 1.

Table 1. Nominal composition of the alloy $\mathrm{FeCrCoNiAl}_{1.8} \mathrm{Cu}_{0.5}$.

\begin{tabular}{ccccccc}
\hline Element & Al & Fe & Cr & Co & Ni & Cu \\
\hline wt. $\%$ & 15.9 & 18.3 & 17 & 19.3 & 19.2 & 10.4 \\
\hline
\end{tabular}

Powders of FeCrCoNiAl1.8Cu0.5 have been obtained by gas atomisation (N2) in a lab scale atomiser equipped with an induction furnace (Atomising Systems Limited, Sheffield, UK). Atomised powders were characterised by X-ray diffraction (XRD) (Siemens D5000 diffractometer by Siemens, München, Germany) and for data acquisition and processing, Xpert Highscore software was used (version 2.2.5 Malvern Panalytical, Amsterdam, The Netherlands). Basic characterisation of powders was accomplished by particle morphology examination using scanning electron microscope (FEI Teneo FEG-SEM, Hilsboro, OR, USA), oxygen content measurement (LECO TC 500 equipment by LECO, St Joseph, MI, USA) and density determination by a He pycnometer (AccuPyc 1330 by Micromeritics, Norcross, GA, USA).

The samples were also processed 1 by conventional press and sintering (P\&S) as reference materials. Discs of $16 \mathrm{~mm}$ were compacted in a double effect uniaxial die up to $585 \mathrm{MPa}$, to improve the compressibility powders were mixed with $3 \mathrm{wt}$ \% Acrawax. Sintering was carried out with a heating rate of $5{ }^{\circ} \mathrm{C} / \mathrm{min}$ with a dwell of $30 \mathrm{~min}$ at $500{ }^{\circ} \mathrm{C}$ to remove the wax, and then heated up to $1320^{\circ} \mathrm{C}$ for 4 hours to densify the material, and the cooling rate was about $2-5^{\circ} \mathrm{C} / \mathrm{min}$. This high temperature was selected to facilitate the full densification of the alloy due to the lack of pressure or high heating/cooling rates during sintering, below the melting temperature of the powder. Although some minor liquid may appear on the sintering stage of the P\&S process, in the calorimetry tests of the blended powder, melting was not detected below $1350{ }^{\circ} \mathrm{C}$ [36], and taking account of the already stable solid solution of the prealloyed powder, liquid is not expected during the consolidation steps.

In order to identify the effect on the microstructural evolution for the SPS processing route, the final temperature and dwell times were modified. Initially, sintering up to $1000{ }^{\circ} \mathrm{C}$ could avoid further $\mathrm{Cu}$ segregations by not reaching its melting point of $1080{ }^{\circ} \mathrm{C}$. However, for better consolidation, the samples were also sintered at $1100^{\circ} \mathrm{C}$. Regarding the holding time, it was set to 1 and $5 \mathrm{~min}$ to study possible implications on the microstructure.

The temperature was measured proximate to the powder with a $\mathrm{K}$ type thermocouple placed inside a $6 \mathrm{~mm}$ hole in the middle section of the die in a (Dr Sinter, SPS-1050CE from SPS Syntex). Pressure $(50 \mathrm{MPa})$ and heating rate $\left(200{ }^{\circ} \mathrm{C} / \mathrm{min}\right)$ were kept constant 
in all sintering cycles with current densities around $1.2 \mathrm{kA} / \mathrm{cm}^{2}$. Finally, to avoid carbon contamination during consolidation, the die wall was covered with boron nitride to hinder carbon diffusion inwards.

For ERS processing, the powder was filled in an NZP (sodium zirconium phosphate) die of $10 \mathrm{~mm}$ diameter between two copper electrodes. The maximum applied current density was between 7.5 and $8 \mathrm{kA} / \mathrm{cm}^{2}$ with a holding time of 300,500, and $700 \mathrm{~ms}$. Maximum load was $200 \mathrm{MPa}$.

These techniques have been chosen because their different sintering times permit studying the phase formation and microstructure evolution of the alloy. In order to compare the sintering time of each technique, a summary of the sintering conditions applied in $P \& S$, SPS, and ERS is shown in Table 2. Figure 1 shows a scheme in which the holding time applied and the total sintering time have been compared (considering the holding time and the heating and cooling rates).

Table 2. Summary of conditions applied on sintering by conventional pressing and sintering (P\&S), spark plasma sintering (SPS), and electrical resistance sintering (ERS).

\begin{tabular}{ccccc}
\hline P\&S & Sintering Temperature $\left({ }^{\circ} \mathbf{C}\right)$ & Holding Time (h) & Heating Rate $\left({ }^{\circ} \mathbf{C} / \mathbf{m i n}\right)$ & Total Sintering Time (h) \\
\hline P\&S & 1320 & 4 & 5 & 13.3 \\
\hline P\&S & Sintering Temperature $\left({ }^{\circ} \mathbf{C}\right)$ & Holding Time (min) & Heating Rate $\left({ }^{\circ} \mathbf{C} / \mathbf{m i n}\right)$ & Total Sintering Time (min) \\
\hline SPS_1 & 1000 & 1 & 200 & 12 \\
SPS_2 & 1000 & 5 & 200 & 22.4 \\
SPS_3 & 1100 & 1 & 200 & 11.9 \\
SPS_4 & 1100 & 5 & 200 & 22.5 \\
\hline ERS & Current Intensity (kA) & Holding Time (ms) & Heating Rate $\left({ }^{\circ} \mathbf{C} / \mathbf{m i n}\right)$ & Total Sintering Time (s) \\
\hline ERS_1 & 8 & 500 & - & 0.5 \\
ERS_2 & 7.5 & 300 & - & 0.3 \\
ERS_3 & 7.5 & 500 & - & 0.5 \\
ERS_4 & 7.5 & 700 & - & 0.7 \\
\hline
\end{tabular}

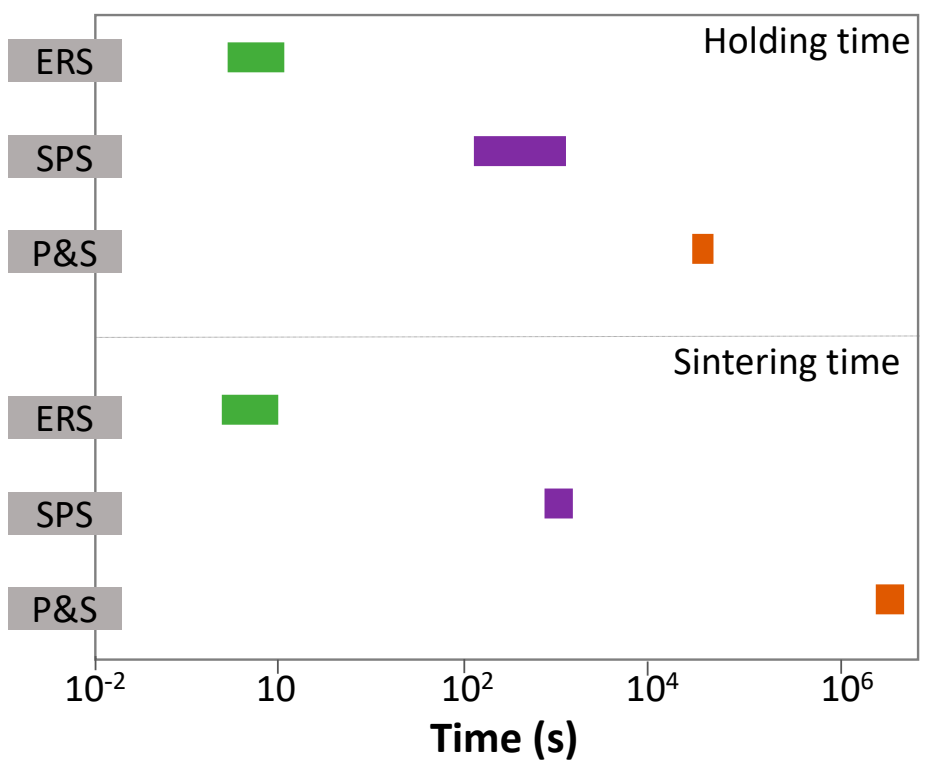

Figure 1. Scheme of relationships between sintering methods and parameters.

Sintered samples were characterised by X-ray diffraction (XRD), and microstructure was examined using SEM (scanning electron microscope) coupled with an EDX (energydispersive X-ray) detector. The oxygen content was measured again after sintering by LECO oxygen analyser. Vickers hardness measurements were performed to state the 
different features of microstructures (Wilson Wolpert $930 \mathrm{~N}$ by Wilson Wolpert, Fort Worth, TX, USA).

From XRD analysis of sintered samples the lattice misfit $(\varepsilon)$ between BCC and BCC/B2 phases is calculated using the Equation (1):

$$
\varepsilon=2 \times \frac{a_{\mathrm{B} 2}-a_{\mathrm{BCC}}}{a_{\mathrm{B} 2}+a_{\mathrm{BCC}}}
$$

where $a_{\mathrm{B} 2}$ and $a_{\mathrm{BCC}}$ are the lattice constants of BCC/B2 and BCC phases, respectively [37].

\section{Results}

\subsection{Powder Production: Gas Atomisation}

The basic characteristics of the atomised powders are shown in Figure 2. Powder particles exhibit spherical morphology, a narrow particle size distribution with a D50 $=40 \mu \mathrm{m}$, and a composition quite similar to the theoretical. One of the advantages of gas atomisation is the rapid solidification of the alloy $\left(10^{5}-10^{6} \mathrm{~K} / \mathrm{s}\right)[38]$, which inhibits phase separation and allows the formation of one simple BCC phase.

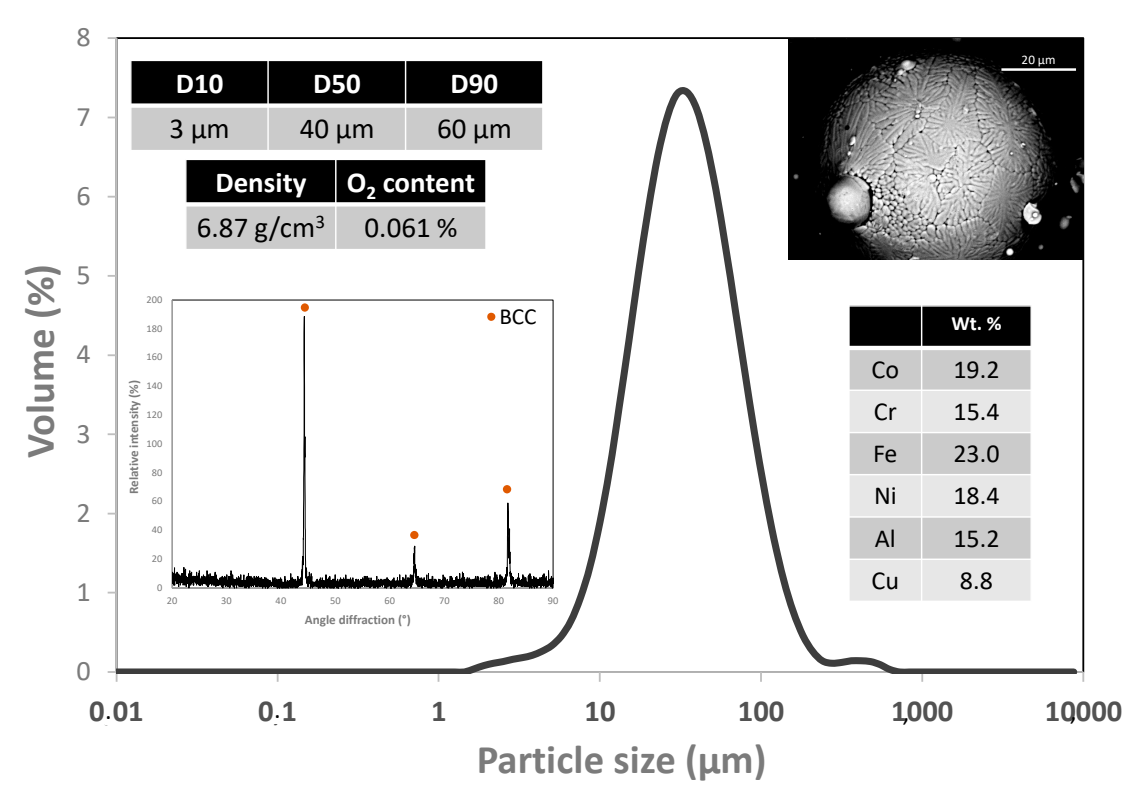

Figure 2. Basic characteristics of the $\mathrm{FeCrCoNiAl}{ }_{1.8} \mathrm{Cu}_{0.5}$ atomised powder.

However, the high solidification rate achieved in gas atomisation has not prevented some segregation of the $\mathrm{Cu}$ as shown in the compositional analysis of the particle cross section displayed in Figure 3. This image shows a homogeneous distribution of the alloying elements, except for a few brighter areas on grain boundaries which corresponds with higher $\mathrm{Cu}$ concentration. This $\mathrm{Cu}$ segregation has been also reported in other $\mathrm{Cu}$-containing HEAs as a FCC crystalline phase $[39,40]$. However, on the XRD, no trace of this minor FCC/Cu segregation is found, only BCC structure. 


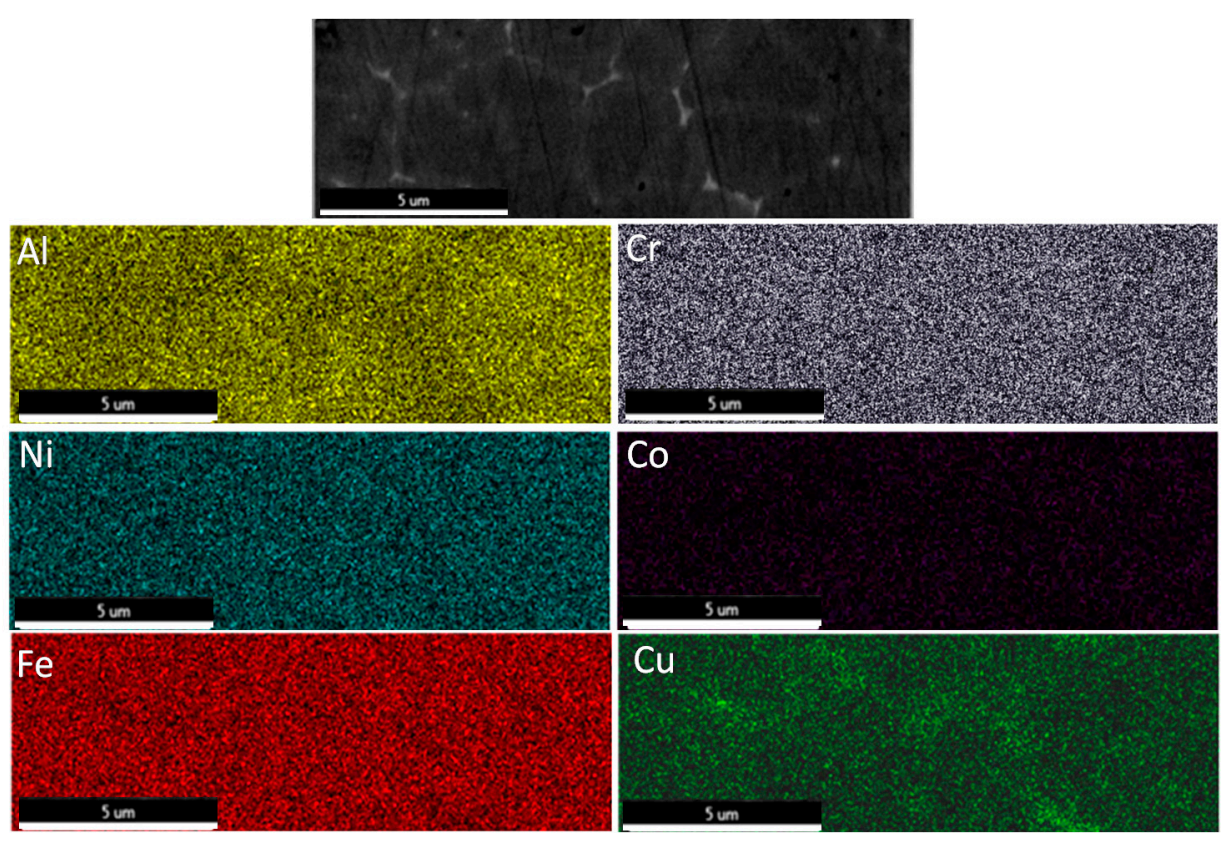

Figure 3. Compositional analysis by EDX of the $\mathrm{FeCrCoNiAl}_{1.8} \mathrm{Cu}_{0.5}$ powder particle cross section.

\subsection{Spark Plasma Sintering}

In order to find the optimum conditions to obtain a fully densified sample, several parameters were studied, such as temperature and holding time. The sample evolution during sintering was recorded by monitoring the displacement of the punches, Figure 4, where increasing values correspond to the punches approaching compression, and decreasing or negative values to punches withdrawal movement, i.e., sample dilatation.

All monitored cycles follow similar patterns, and according to this, it is possible to describe the SPS process in 3 stages. In the first stage, the equipment applies the uniaxial load until it reaches $50 \mathrm{MPa}$ and it is kept constant along the process. During this step, the particles reorganise to a more compact arrangement. In the second stage, between 200 and $500{ }^{\circ} \mathrm{C}$, there is competition between thermal expansion related to the graphite punches and the HEA versus the compression produced by the punches, yielding to a plateau and subsequent negative displacement. The third stage starts about $600{ }^{\circ} \mathrm{C}$, where the displacement changes starting with the sintering process up to about $990^{\circ} \mathrm{C}$ on the SPS-1000 samples (Figure 4a). For SPS-1100 samples (Figure 4b), this phenomenon approximately occurs at an earlier temperature of $900^{\circ} \mathrm{C}$. Above $1000{ }^{\circ} \mathrm{C}$, the volume shrinkage from the porosity reduction finishes. From $1050^{\circ} \mathrm{C}$, the punch shows a negative displacement indicating the thermal expansion of the bulk sample already fully densified at that temperature, this last phenomenon has been already seen on some SPS studies [41]. Once the holding time has finished, the equipment releases the applied pressure and starts cooling the HEA. 


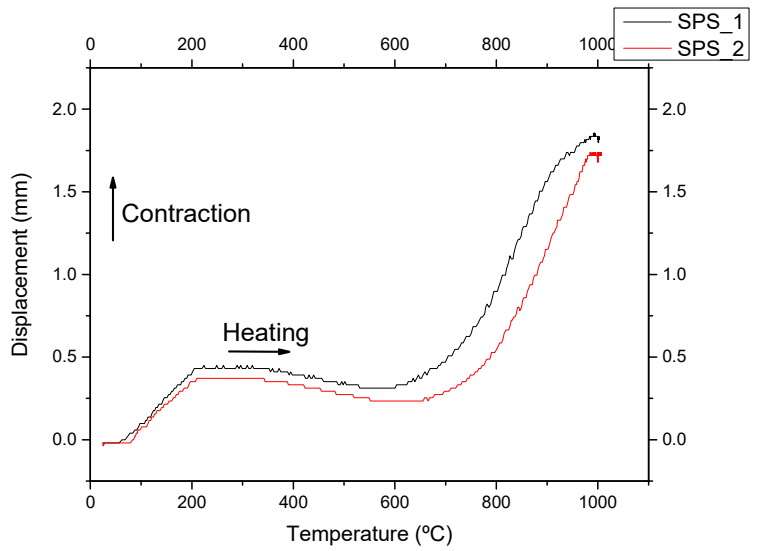

(a)

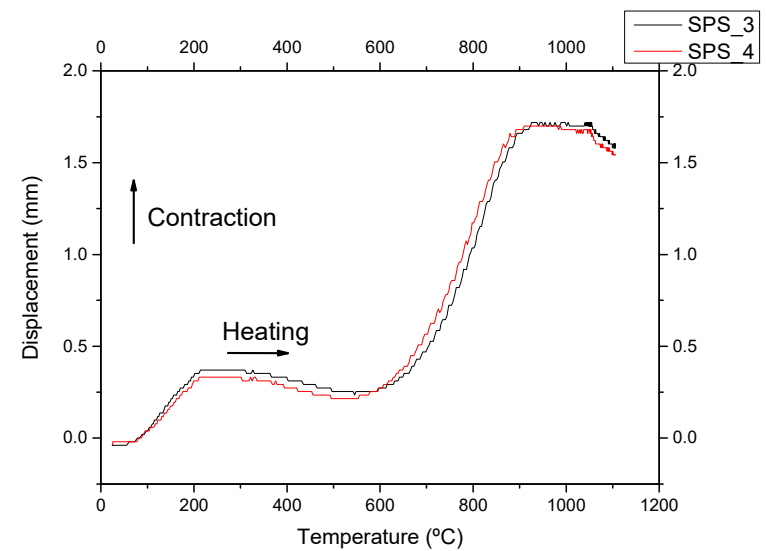

(b)

Figure 4. Vertical displacement evolution for (a) SPS_1 and SPS_2 and (b) SPS_3 and SPS_4 sintering cycles.

From Figure 5, the microstructure of the samples sintered at 1000 and at $1100{ }^{\circ} \mathrm{C}$ can be observed. Samples sintered at higher temperature present higher densification than samples sintered at $1000{ }^{\circ} \mathrm{C}$. The samples sintered at $1000^{\circ} \mathrm{C}$ (Figure 5a,b) reveal a lower densification due to the porosity close to some rounded-shape particles which correspond with the initial powder particles. Confirmation that the densification process has not been completed is recorded in the displacement versus temperature curve (Figure 4a). However, the study of the microstructure of these samples sintered at $1000{ }^{\circ} \mathrm{C}$ could help to understand the sintering behaviour of the alloy. By increasing the sintering temperature and improving densification, a refinement of the microstructure and a reduction in porosity are observed.

All the samples show the presence of two main phases: a grey matrix and a brighter elongated and crisscrossed phase. Moreover, the microstructures present a third bright phase in the grain boundaries which could correspond with $\mathrm{Cu}$ segregation as has been observed in the atomised powder in Figure 3.

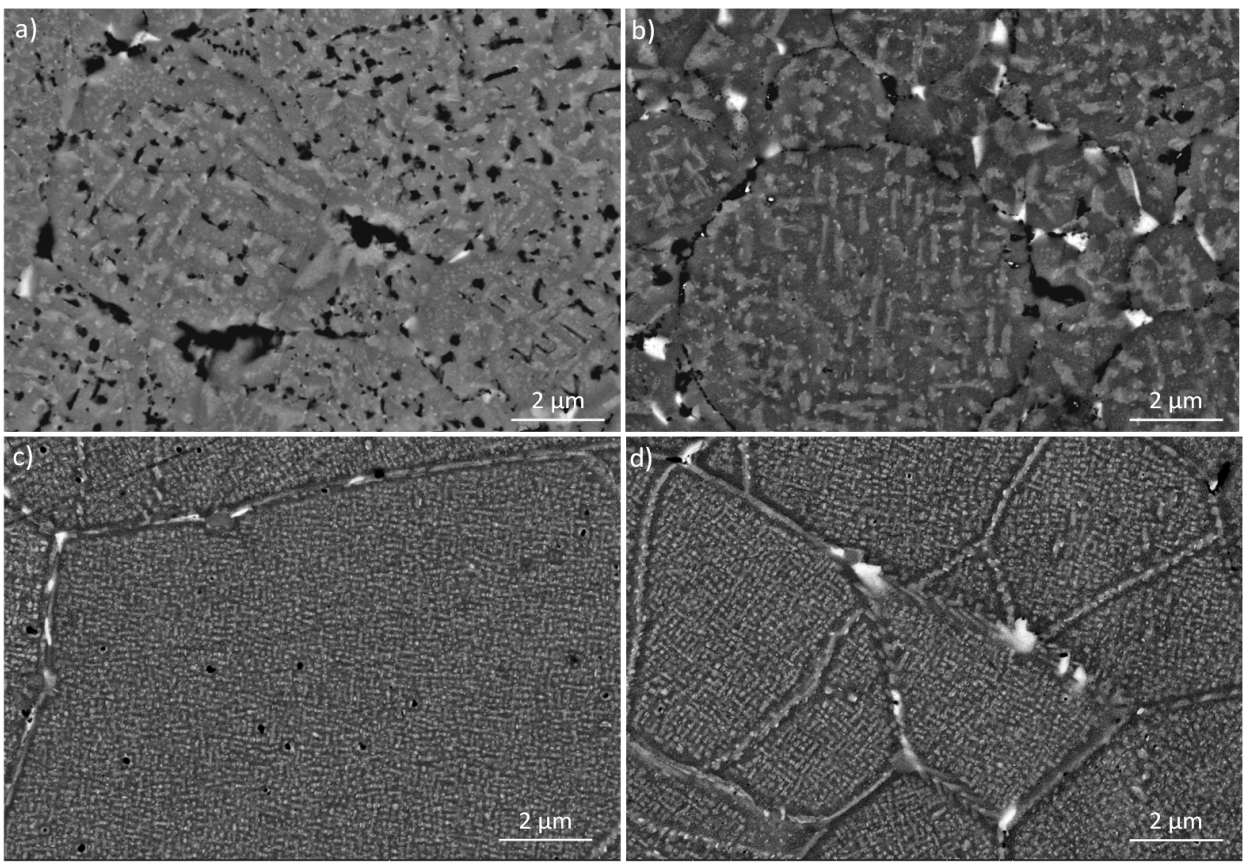

Figure 5. Microstructure of samples sintered by SPS: (a) and (b) at $1000{ }^{\circ} \mathrm{C}$ for 1 and $5 \mathrm{~min}$ as holding time, respectively; (c) and (d) $1100{ }^{\circ} \mathrm{C}$ for 1 and 5 min as holding time, respectively. 
The diffraction patterns of the SPS samples shown in Figure 6 indicate the existence of two phases corresponding with a BCC phase and a BCC-B2 phase which can be related with the two phases observed in their microstructures. In addition, the diffractograms present a shoulder in the (110) peak around a diffraction angle of $43^{\circ}$ which corresponds with a (111) peak of an FCC structure with a lattice parameter of $3.62 \AA$. Furthermore, a movement of the main BCC peak (110) towards slightly higher angles in the samples sintered at $1100{ }^{\circ} \mathrm{C}$ could indicates a variation in the $\mathrm{Cu} / \mathrm{Al}$ diffused ratio in the $\mathrm{BCC}$ during sintering with the consequent change of the reticular parameter.

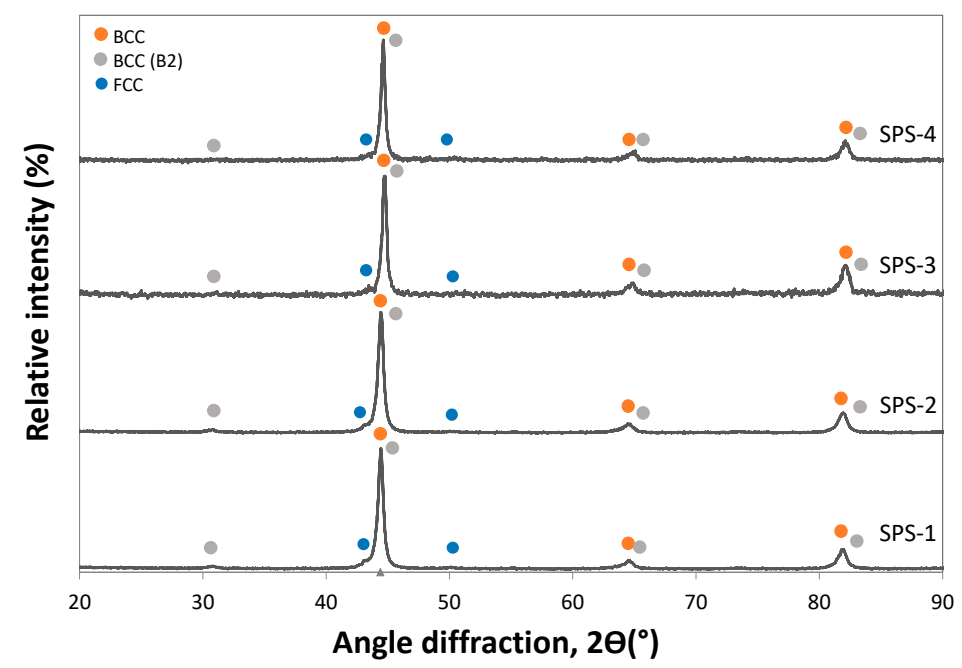

Figure 6. XRD analysis of samples sintered by SPS.

\subsection{Conventional Pressing and Sintering}

The results of the characterisation of the $\mathrm{FeCrCoNiAl}_{1.8} \mathrm{Cu}_{0.5}$ manufactured by P\&S are shown in Figure 7. The general observation of the microstructure in Figure 7a reveals an important coarsening of the phases. As with the SPS samples, the alloy sintered by P\&S presented two phases, a grey matrix and a dark phase elongated and crisscrossed.

Although the contrast of the crisscrossed phase is dark and not bright as in the SPS samples, the diffractogram in Figure $7 \mathrm{~b}$ reveals the presence of the same phases: BCC, FCC, and BCC-B2, so the different contrast is due to the etching during the metallographic preparation. It is worth highlighting the presence of chromium carbides found in the compositional analysis showed in Figure 7a due to the contamination from the wax used as lubricant in the pressing stage.
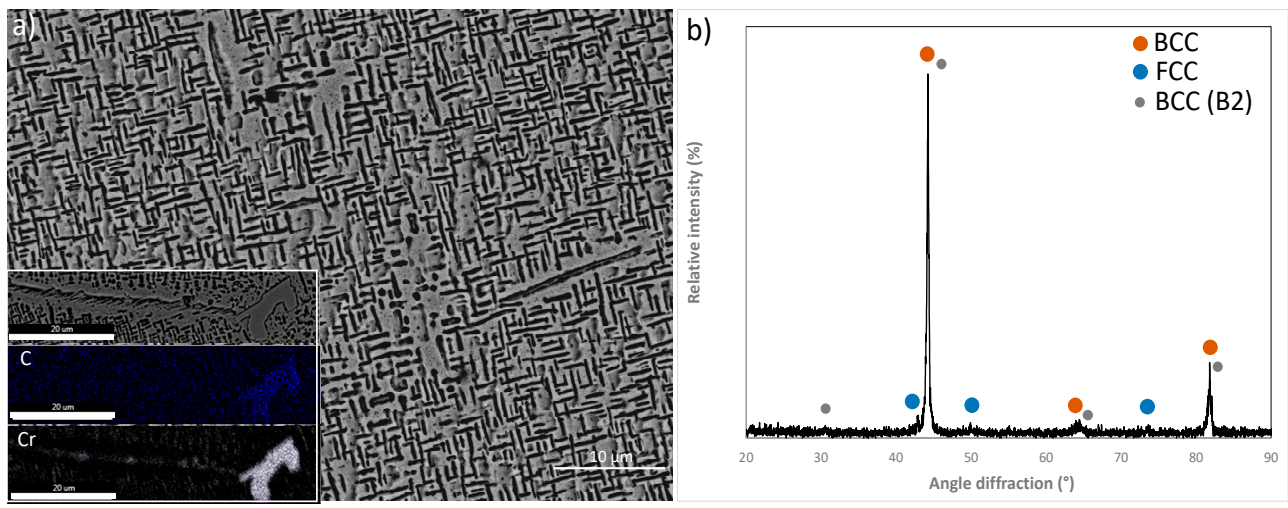

Figure 7. (a) Characterisation of $\mathrm{FeCrCoNiAl}_{1.8} \mathrm{Cu}_{0.5}$ processed by $\mathrm{P} \& \mathrm{~S}$ : microstructure, and details of $\mathrm{C}$ and $\mathrm{Cr}$ analysis on a GB. (b) X-ray diffractogram. 


\subsection{Electrical Resistance Sintering}

Figure 8 shows the microstructures of the samples sintered by ERS which, contrary to sintering by the techniques described above, show a single phase and grain refinement.

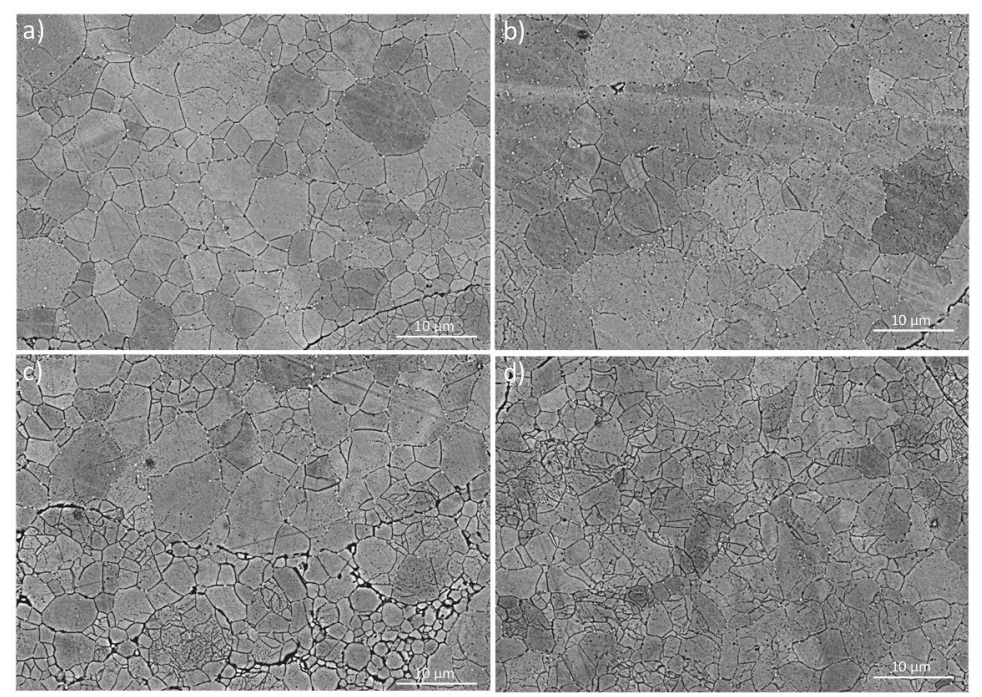

Figure 8. Microstructures of samples sintered by ERS under (a) $8 \mathrm{kA}$ and $500 \mathrm{~ms}$ and (b), (c) and (d) $7.5 \mathrm{kA}$ and 300, 500, and $700 \mathrm{~ms}$, respectively.

However, it shows small bright precipitates on the grain boundary. Comparing the microstructures of these samples sintered with different current intensity and time, it is observed that the sample sintered with $8 \mathrm{kA}$ as current intensity (which correspond with the highest sintering temperature) achieves a better densification than samples sintered with $7.5 \mathrm{kA}$.

In XRD diffractograms of ERS samples in Figure 9, it is observed, as in the microstructure, that they present a single phase with BCC structure and only in the diffractogram of the sample sintered at $8 \mathrm{kA}$ is a small peak at $30^{\circ}$ intuited, which could imply the presence of a BCC-B2 phase.

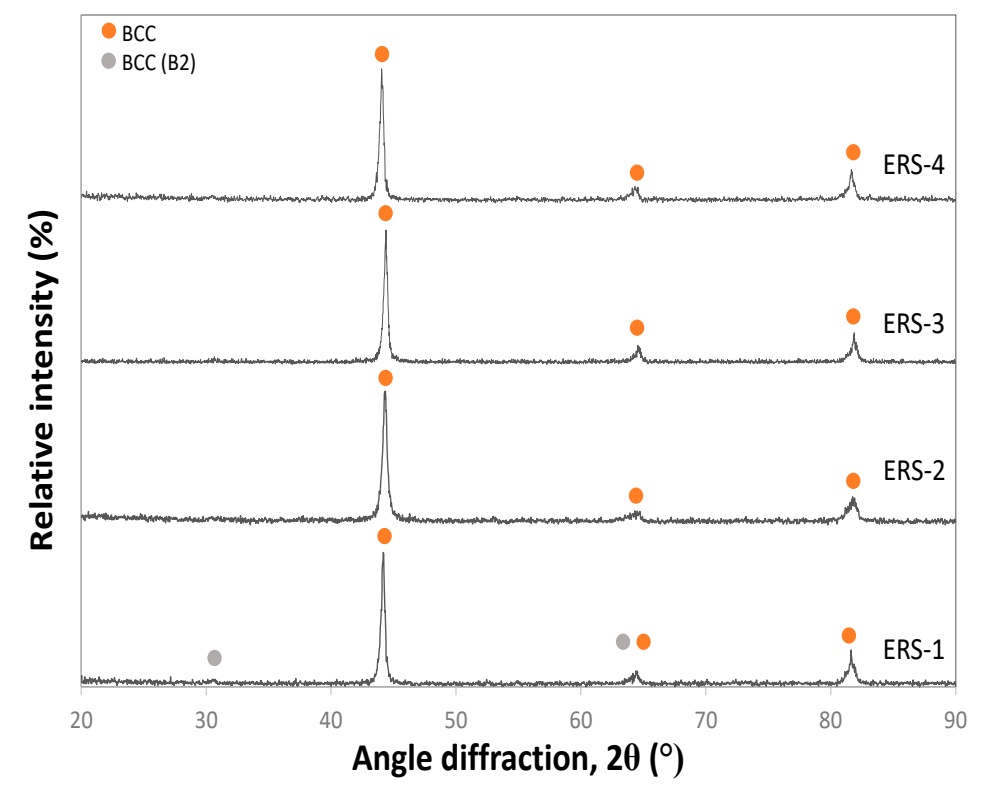

Figure 9. XRD analysis of samples sintered by ERS. 


\section{Discussion: Evolution of the Microstructure with the Sintering Time}

The results of the sintering of the alloy $\mathrm{FeCrCoNiAl}_{1.8} \mathrm{Cu}_{0.5}$ using three techniques P\&S, SPS, and ERS have been presented. The processing time of these sintering techniques is very different being a conventional sintering technique (P\&S), a fast sintering technique (SPS), and an ultrafast sintering technique (ERS).

To study, in detail, the differences found in the microstructure of the sintered samples by means of the three techniques, the compositional analysis of their microstructures is shown in Table 3. First, it can be concluded that by increasing the sintering time, the segregation of $\mathrm{Cu}$ increases. However, the great difference in the microstructures is related with the phase separation which increases with the sintering time. In view of the compositional mapping of Figure 10 and the composition analysis on Table 3, the bright phase would correspond to a $\mathrm{FeCr}$-rich composition and the grey matrix with $\mathrm{NiAl}$, and comparing the results with those in the literature, the microstructure is a disordered BCC phase rich in Fe and $\mathrm{Cr}$ and an ordered B2 phase rich in AlNi. Co shows great miscibility with both phases with a slightly tendency towards AlNi. The calculated volume fractions from each phase (Table 3) show similar values for P\&S and SPS methods, although the coarsening of the phases is quite evident in the images. Finally, only one phase is analysed on ERS method.

The role of the fabrication method inherently implies the influence of the cooling rates and the kinetic parameters in the phase formation. While the solid solution phase is stabilised at a faster cooling rate, a slower cooling rate leads to precipitation of more $\mathrm{Cu}$-rich phases and its coarsening. Some authors have studied the cooling rate as an important factor in the phase formation for the same HEA family [42].

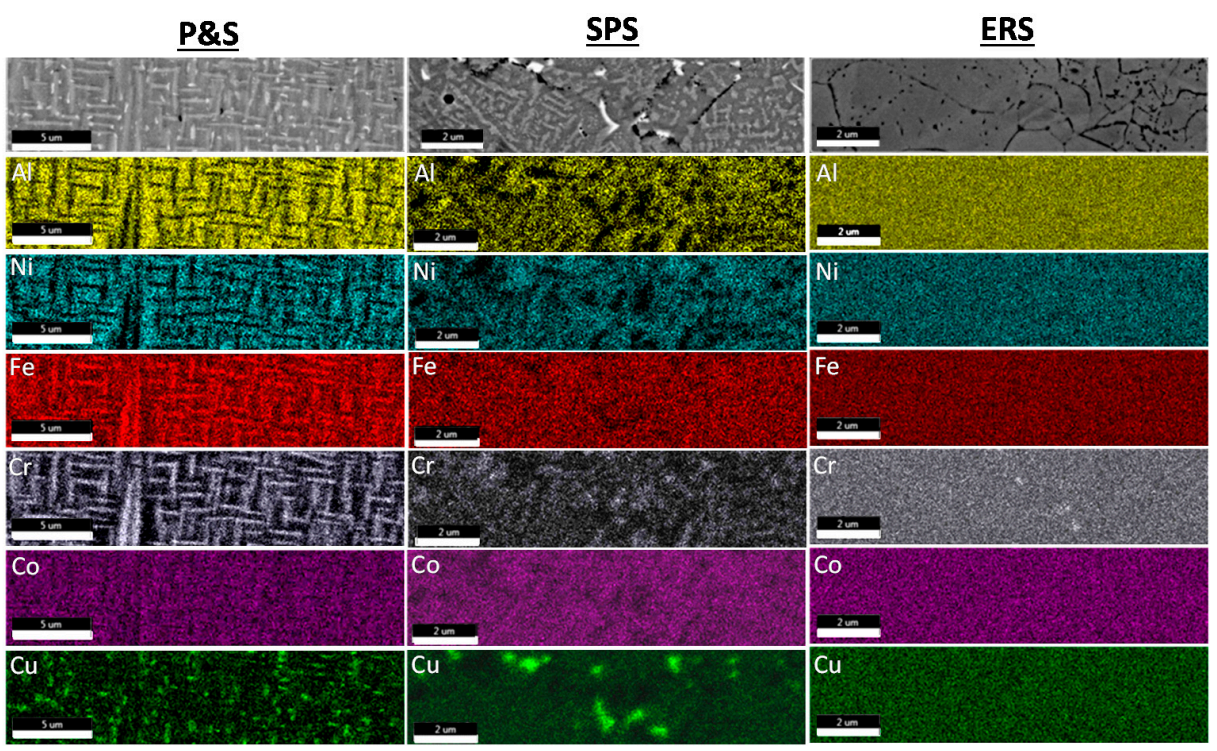

Figure 10. EDS area mapping conducted on $\mathrm{FeCrCoNiAl}_{1.8} \mathrm{Cu}_{0.5} \mathrm{HEA}$ by sintering methods. 
Table 3. Compositional and volumetric fraction analysis performed on the phases from mapping tests.

\begin{tabular}{ccccccccc}
\hline \multirow{2}{*}{ Method } & \multirow{2}{*}{ Phase } & \multicolumn{7}{c}{ Composition (at. \%) } \\
\cline { 3 - 9 } & & Cr & Co & Fe & Ni & Al & Cu & Vol. \% \\
\hline \multirow{2}{*}{ P\%S } & Fe-Cr-rich & 19.3 & 16 & 24.7 & 14.8 & 17.5 & 7.7 & 44 \\
& Al-Ni-rich & 10.6 & 18.1 & 20.2 & 19.1 & 23.1 & 8.6 & 50 \\
& Cu-rich & 4.7 & 12 & 8.6 & 10.9 & 27.3 & 37.7 & $<5$ \\
\hline \multirow{2}{*}{ SPS } & Fe-Cr-rich & 25.7 & 16.1 & 12.9 & 21.5 & 20 & 3.7 & 41 \\
& Al-Ni-rich & 20.4 & 10.8 & 9.8 & 12.2 & 41.7 & 4.9 & 54 \\
& Cu-rich & 19.4 & 10.1 & 8.9 & 11.7 & 24.2 & 25.5 & $<5$ \\
\hline \multirow{2}{*}{ ERS } & Homogenous & 23.8 & 12.2 & 11.4 & 15.2 & 29.7 & 7.6 & 95 \\
\hline
\end{tabular}

Phase separation can be explained by thermodynamic properties. System stability depends on the Gibbs free energy that is given by Equation (2):

$$
\begin{aligned}
& \Delta G_{\text {mix }}=\Delta H_{\text {mix }}-T \Delta S_{\text {mix }} \\
& \Delta H_{\text {mix }}=-11.08 \mathrm{~kJ} \cdot \mathrm{mol}^{-1} \\
& \Delta S_{\text {mix }}=14.36 \mathrm{~J} \cdot \mathrm{k}^{-1} \cdot \mathrm{mol}^{-1}
\end{aligned}
$$

where $\Delta H_{\text {mix }}$ and $\Delta S_{\text {mix }}$ are the changes of mixing enthalpy and mixing entropy respectively, and $\mathrm{T}$ is temperature. Due to the random distribution of a high number of elements in HEAs, the configurational entropy is higher than in ordered and intermetallic alloys, being the main actor in the stability of random solid solutions when the mixing enthalpy is close to zero [42]. However, when there is an increase in the mixing enthalpy (in absolute value), both this and the nonconfigurational entropy determine the phase stability and give rise to a two-phase mixture or a miscibility gap.

$\mathrm{Xu}$ et al. [42] recently analysed the effects of cooling rates and mixing enthalpy on phase formation on the CrCoFeNiAlxCu family. Showing how the mean $\Delta H_{\text {mix }}$ is certainly related to solid solution phase stability although the core mechanism is not simple and straightforward. With increasing $\mathrm{Al}$ ratio in the $\mathrm{CrCoFeNiAl}_{\mathrm{x}} \mathrm{Cu}$ family alloy, dominant phase changes from FCC to BCC and Tong et al. [17] suggested the appearance of an eutectic point between $x=0.8$ and $x=1.0$. These BCC-dominant HEAs have shown to have a larger number of phases. The rise of the miscibility gap could be supressed at small or close to zero $\Delta H_{\text {mix }}$ as $\mathrm{Xu}$ et al. [42] demonstrate at $x=0.5 \mathrm{Al}$ molar ratio. This value is far lower than the CrCoFeNiAl1.8Cu0.5 of the present study, which has a $\Delta H_{\text {mix }}$ of $-11.08\left(\mathrm{~kJ} \cdot \mathrm{mol}^{-1}\right)$, a very negative value which is attributed to a more complex phase constitution and strong local chemical ordering [42].

One way to approximate the mixing enthalpy is by using binary alloys $\left(\Delta H_{m i x}-\mathrm{AB}\right)$. As binary values $\left|\Delta H_{m i x}-\mathrm{AB}\right|$ increases, the elements and phases in HEAs tends to separate $[22,43]$. Applying these concepts to the alloy FeCrCoNiAl1.8Cu0.5, the observed phase separation and segregation can be argued by looking at the binary mixing enthalpy of the HEA in Figure 11. The most negative mixing enthalpy of the binary systems AlNi and $\mathrm{AlCo}$ as it is shown in the diagram, -22 and $-19 \mathrm{~kJ} \cdot \mathrm{mol}^{-1}$, respectively [44], favours the formation of the ordered solid solution (B2-type) [45]. The segregation of $\mathrm{Cu}$ can be also be justified by the positive mixing enthalpy of the systems $\mathrm{CuCr} ; \mathrm{CuCo}, \mathrm{CuFe}$, and $\mathrm{CuNi}$, also shown in the diagram of Figure 11 [44]. As can be seen in the evolution of the microstructure of the sintered alloy with different sintering times, an increase in sintering time favours phase separation because the most thermodynamically stable system is formed while the ultrafast sintering limits phase separation, achieving a single random solid solution and even being thermodynamically unfavourable. 


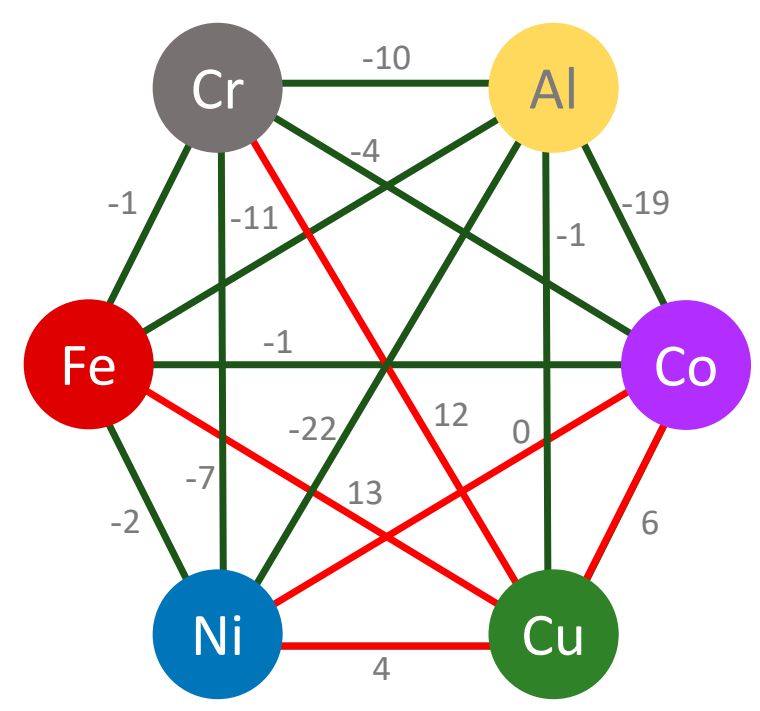

Figure 11. Mixing enthalpy (kJ/mol) of binary systems in the alloy FeCrCoNiAlCu [44].

BCC-B2 phase separation could also explain the presence of a peak corresponding with a FCC phase in the XRD diffractograms of P\&S and SPS samples (Figures 6 and 7). The separation of the $\mathrm{B} 2$ phase decreases the $\mathrm{Al}$ content in the $\mathrm{BCC}$ matrix, the $\mathrm{Al}$ content being a key factor of phase formation in the HEAs of the FeCrCoNi family.

There are several works in which it is studied how the percentage of Al determines the crystalline structure of the solid solution formed BCC, FCC, or BCC + FCC due to the lattice distortion and tendency to form a structure with a lower atomic-packing efficiency [46-49]. In the case of the alloy studied in this work, $\mathrm{FeCrCoNiAl}_{1.8} \mathrm{Cu}_{0.5}$, it has the aim of obtaining a BCC solid solution and, hence, the separation of phases can contribute to the formation of a solid phase solution with a BCC + FCC crystalline structure. The presence of segregated $\mathrm{Cu}$ could contribute to the appearance of the FCC peak in the XRD, although according to the compositional analysis of the grains, the segregated $\mathrm{Cu}$ is not enough to show such intense reflexion.

Another relevant aspect when evaluating the properties of HEAs in relation to their microstructure is the morphology of the B2 phase, which is attributed to the lattice misfit between $\mathrm{B} 2$ and BCC phases and, thus, a low misfit $(\varepsilon=0.2 \%)$ will give rise to rounded nanoprecipitates which improve the mechanical properties of the alloy considerably; a moderate misfit $(\varepsilon=0.4-0.6 \%$ ) will lead to cuboidal precipitates with larger size and a high misfit value $\varepsilon>0.6 \%$ ) will lead to weave-like precipitates with larger size, and it is in this case when an embrittlement of the alloy occurs $[37,48,50]$. FeCrCoNiAl ${ }_{1.8} \mathrm{Cu}_{0.5}$ shows $\varepsilon=0.95 \%$ when sintered by SPS and $\varepsilon=1.10 \%$ when sintered by P\&S. This unfavourable lattice misfit is caused by the large composition difference between BCC and B2 phases and is responsible for the crisscrossed morphology of phase B2. In the alloy sintered by ERS and $8 \mathrm{kA}$, the presence of B2 is also observed in the diffractogram of the sample, although it is not appreciable in the image of its microstructure, the calculation of its misfit reveals a moderate value $(\varepsilon=0.44 \%)$, so the presence of B2 is not ruled out, but in this case, it would be nanosized and would not have been detected with the techniques used.

All the microstructural changes studied in relation to the sintering time are returned in changes in the hardness (Figure 12), finding the highest values to be in the sintered samples using the ultrafast sintering technique rather than the samples sintered by SPS and $P \& S$. As seen in the discussion of microstructural changes due to sintering time, the factors responsible for such differences in hardness are diverse. In the first place, the phase separation and the thickening of the B2 phase plays a detriment to the hardness in relation to the alloy with a single disordered solid solution. However, also, as previously explained, the phase separation decreases the $\mathrm{Al}$ content in the solid solution favouring the presence of the FCC phase, being less hard than the BCC phase. Al has been proven to 
show a similar effect as carbon in steels in substantially increasing the hardness in HEA as well as promoting the formation of BCC phases. Yeh [46] has previously studied the modifications that $\mathrm{Al}$ addition implies in the hardness of the $\mathrm{Al}_{\mathrm{x}} \mathrm{CoCrCuFeNi}$ alloy due to the modification of the crystalline structure from FCC to BCC.

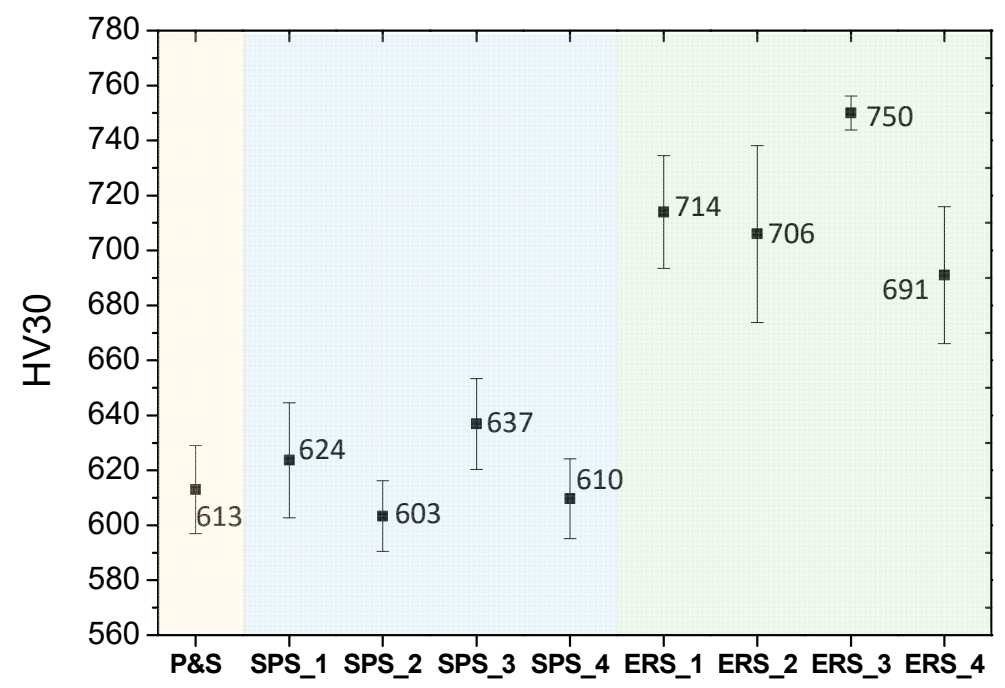

Figure 12. Hardness of samples sintered by P\&S, SPS, and ERS.

Finally, one of the advantages of this ultrafast sintering technique, ERS, is the capability to consolidate the powders in absence of protective atmosphere. Regarding the oxygen content measurements exhibited in Table 4, the oxygen content of ERS samples sintered show comparable values than samples sintered by techniques using protective atmosphere being low oxygen values in all the sintered samples.

Table 4. Oxygen content (wt.\%) of $\mathrm{FeCrCoNiAl}_{1.8} \mathrm{Cu}_{0.5}$ sintered by P\&S, SPS, and ERS.

\begin{tabular}{ccccccccccc}
\hline Method & Powder & P\&S & SPS_1 & SPS_2 & SPS_3 & SPS_4 & ERS_1 & ERS_2 & ERS_3 & ERS_4 \\
\hline $\mathrm{O}(\%)$ & 0.06 & 0.03 & 0.08 & 0.05 & 0.03 & 0.04 & 0.03 & 0.04 & 0.09 & 0.08 \\
\hline
\end{tabular}

\section{Conclusions}

The evolution of microstructures of the $\mathrm{FeCrCoNiAl}_{1.8} \mathrm{Cu}_{0.5}$ HEA sintered by the PM conventional sintering route $\mathrm{P} \& \mathrm{~S}$, a fast sintering technique (SPS), and an ultrafast sintering technique (ERS) has been studied, and the results are explained in relation to the different sintering times applied in each consolidation technique. The study of the results reveals that the total sintering time will play a key role in the phase formation kinetics, which is summarised in the following points:

- An increase in the total sintering time favours the separation of phases, stabilises the formation of the ordered $\mathrm{B} 2$ phase rich in $\mathrm{AlNiCo}$ and the subsequent appearance of minor FCC.

- By reducing the total sintering time using an ultrafast sintering technique, grain coarsening and element segregation $(\mathrm{Cu})$ are minimised.

- The alloy consolidated by ERS shows the highest hardness values. In addition, the oxygen content is similar to that of consolidation techniques which use a protective atmosphere.

- $\quad$ ERS was presented as a novel and promising technique to consolidate HEAs, avoiding segregation and maintaining the crystalline structure.

Author Contributions: Conceptualisation J.C. and P.A.; methodology E.R., P.A., M.C. and J.C.; Analysis and investigation: E.R., P.A., M.C. and J.C.; writing E.R., P.A.; supervision P.A., M.C., M.A.L. and J.C. All authors have read and agreed to the published version of the manuscript. 
Funding: The authors gratefully acknowledge the financial support of MAT4.0-CM project funded by Madrid region under programme S2018/NMT-4381. J. Cornide also acknowledges funding from the Spanish Ministry of Science and Innovation (IJCI-2017-31348).

Institutional Review Board Statement: Not applicable.

Informed Consent Statement: Not applicable.

Data Availability Statement: No data available.

Conflicts of Interest: The authors declare no conflict of interest. The funders had no role in the design of the study; in the collection, analyses, or interpretation of data; in the writing of the manuscript; or in the decision to publish the results.

\section{References}

1. Toda-Caraballo, I.; Rivera-Díaz-Del-Castillo, P. A criterion for the formation of high entropy alloys based on lattice distortion. Intermetallics 2016, 71, 76-87. [CrossRef]

2. Qiu, X.-W. Microstructure and properties of $\mathrm{AlCrFeNiCoCu}$ high entropy alloy prepared by powder metallurgy. J. Alloys Compd. 2013, 555, 246-249. [CrossRef]

3. Cantor, B.; Chang, I.; Knight, P.; Vincent, A. Microstructural development in equiatomic multicomponent alloys. Mater. Sci. Eng. A 2004, 375-377, 213-218. [CrossRef]

4. Calvo-Dahlborg, M.; Brown, S. Hume-Rothery for HEA classification and self-organizing map for phases and properties prediction. J. Alloys Compd. 2017, 724, 353-364. [CrossRef]

5. Poletti, M.; Battezzati, L. Electronic and thermodynamic criteria for the occurrence of high entropy alloys in metallic systems. Acta Mater. 2014, 75, 297-306. [CrossRef]

6. Glasscott, M.W.; Pendergast, A.D.; Goines, S.; Bishop, A.R.; Hoang, A.T.; Renault, C.; Dick, J.E. Electrosynthesis of high-entropy metallic glass nanoparticles for designer, multi-functional electrocatalysis. Nat. Commun. 2019, 10, 1-8. [CrossRef]

7. Ma, S.G.; Zhang, S.F.; Gao, M.C.; Liaw, P.K.; Zhang, Y. A Successful Synthesis of the CoCrFeNiAl0.3 Single-Crystal, High-Entropy Alloy by Bridgman Solidification. JOM 2013, 65, 1751-1758. [CrossRef]

8. Xia, S.; Gao, M.C.; Yang, T.; Liaw, P.K.; Zhang, Y. Phase stability and microstructures of high entropy alloys ion irradiated to high doses. J. Nucl. Mater. 2016, 480, 100-108. [CrossRef]

9. Guo, S.; Liu, C. Phase stability in high entropy alloys: Formation of solid-solution phase or amorphous phase. Prog. Nat. Sci. Mater. Int. 2011, 21, 433-446. [CrossRef]

10. Tian, F.; Varga, L.K.; Chen, N.; Shen, J.; Vitos, L. Empirical design of single phase high-entropy alloys with high hardness. Intermetallics 2015, 58, 1-6. [CrossRef]

11. Jiang, L.; Lu, Y.; Jiang, H.; Wang, T.; Wei, B.; Cao, Z.; Li, T. Formation rules of single phase solid solution in high entropy alloys. Mater. Sci. Technol. 2016, 32, 1-5. [CrossRef]

12. Torralba, J.M.; Alvaredo, P.; García-Junceda, A. High-entropy alloys fabricated via powder metallurgy. A critical review. Powder Met. 2019, 62, 84-114. [CrossRef]

13. Munir, Z.A.; Anselmi-Tamburini, U.; Ohyanagi, M. The effect of electric field and pressure on the synthesis and consol-idation of materials: A review of the spark plasma sintering method. J. Mater. Sci. 2006, 41, 763-777. [CrossRef]

14. Hsu, C.-Y.; Juan, C.-C.; Wang, W.-R.; Sheu, T.-S.; Yeh, J.-W.; Chen, S.-K. On the superior hot hardness and softening resistance of AlCoCrxFeMo0.5Ni high-entropy alloys. Mater. Sci. Eng. A 2011, 528, 3581-3588. [CrossRef]

15. Tong, C.J.; Chen, M.R.; Chen, S.K.; Yeh, J.W.; Shun, T.T.; Lin, S.J.; Chang, S.Y. Mechanical performance of the Alx-CoCrCuFeNi high-entropy alloy system with multiprincipal elements. Metall. Mater. Trans. A Phys. Metall. Mater. Sci. 2005, 36, $1263-1271$. [CrossRef]

16. Wu, J.-M.; Lin, S.-J.; Yeh, J.-W.; Chen, S.-K.; Huang, Y.-S.; Chen, H.-C. Adhesive wear behavior of AlxCoCrCuFeNi high-entropy alloys as a function of aluminum content. Wear 2006, 261, 513-519. [CrossRef]

17. Tong, C.J.; Chen, Y.L.; Chen, S.K.; Yeh, J.W.; Shun, T.T.; Tsau, C.H.; Lin, S.J.; Chang, S.Y. Microstructure characterization of AlxCoCrCuFeNi high-entropy alloy system with multiprincipal elements. Metall. Mater. Trans. A Phys. Metall. Mater. Sci. 2005, 36, 881-893. [CrossRef]

18. Tsai, C.-W.; Tsai, M.-H.; Yeh, J.-W.; Yang, C.-C. Effect of temperature on mechanical properties of Al0.5CoCrCuFeNi wrought alloy. J. Alloys Compd. 2010, 490, 160-165. [CrossRef]

19. Manzoni, A.; Daoud, H.; Mondal, S.; Van Smaalen, S.; Völkl, R.; Glatzel, U.; Wanderka, N. Investigation of phases in Al23Co15Cr 23Cu8Fe15Ni16 and $\mathrm{Al} 8 \mathrm{Co} 17 \mathrm{Cr} 17 \mathrm{Cu} 8 \mathrm{Fe} 17 \mathrm{Ni} 33$ high entropy alloys and comparison with equilibrium phases predicted by Thermo-Calc. J. Alloys Compd. 2013, 552, 430-436. [CrossRef]

20. Fan, Q.C.; Li, B.S.; Zhang, Y. Influence of $\mathrm{Al}$ and $\mathrm{Cu}$ elements on the microstructure and properties of (FeCrNiCo)AlxCuy high-entropy alloys. J. Alloys Compd. 2014, 614, 203-210. [CrossRef]

21. Middleburgh, S.; King, D.; Lumpkin, G.; Cortie, M.; Edwards, L. Segregation and migration of species in the CrCoFeNi high entropy alloy. J. Alloys Compd. 2014, 599, 179-182. [CrossRef] 
22. Chang, X.; Zeng, M.; Liu, K.; Fu, L. Phase Engineering of High-Entropy Alloys. Adv. Mater. 2020, 32, 1907226. [CrossRef] [PubMed]

23. Grasso, S.; Sakka, Y.; Maizza, G. Electric current activated/assisted sintering (ECAS): A review of patents 1906-2008. Sci. Technol. Adv. Mater. 2009, 10, 053001. [CrossRef]

24. Lagos, M.; Agote, I.; Schubert, T.; Weissgaerber, T.; Gallardo, J.; Montes, J.; Prakash, L.; Andreouli, C.; Oikonomou, V.; Lopez, D.; et al. Development of electric resistance sintering process for the fabrication of hard metals: Processing, microstructure and mechanical properties. Int. J. Refract. Met. Hard Mater. 2017, 66, 88-94. [CrossRef]

25. Montes, J.M.; Rodríguez, J.A.; Cuevas, F.G.; Cintas, J. Consolidation by electrical resistance sintering of Ti powder. J. Mater. Sci. 2011, 46, 5197-5207. [CrossRef]

26. Montes, J.M.; Cuevas, F.G.; Cintas, J.; Urban, P. A One-Dimensional Model of the Electrical Resistance Sintering Process. Met. Mater. Trans. A 2014, 46, 963-980. [CrossRef]

27. Shon, J.-H.; Park, J.-M.; Cho, K.-S.; Hong, J.-K.; Park, N.-K.; Oh, M.-H. Effects of various sintering methods on microstructure and mechanical properties of CP-Ti powder consolidations. Trans. Nonferrous Met. Soc. China 2014, 24, s59-s67. [CrossRef]

28. Montes, J.M.; Cuevas, F.G.; Ternero, F.; Astacio, R.; Caballero, E.S.; Cintas, J. Medium-Frequency Electrical Resistance Sintering of Oxidized C.P. Iron Powder. Metals 2018, 8, 426. [CrossRef]

29. Lagos, M.; Agote, I.; Leizaola, I.; Lopez, D.; Calero, J. Fabrication of chromium carbide cermets by electric resistance sintering process: Processing, microstructure and mechanical properties. Int. J. Refract. Met. Hard Mater. 2021, 95, 105417. [CrossRef]

30. Alshataif, Y.A.; Sivasankaran, S.; Al-Mufadi, F.A.; Alaboodi, A.S.; Ammar, H.R. Manufacturing Methods, Micro-structural and Mechanical Properties Evolutions of High-Entropy Alloys: A Review. Metals Mater. Int. 2020, 26, 1099-1133. [CrossRef]

31. Tokita, M.; Fantozzi, G.; Estournes, C.; Ortiz, A.L.; Morita, K. Progress of Spark Plasma Sintering (SPS) Method, Systems, Ceramics Applications and Industrialization. Ceramics 2021, 4, 160-198. [CrossRef]

32. McAlpine, S.W.; Logan, J.V.; Short, M.P. Predicting single phase stability and segregation in the NbMoTaTi-(W,V) high entropy alloy system with the vacancy exchange potential. Scr. Mater. 2021, 191, 29-33. [CrossRef]

33. Guo, L.; Gu, J.; Gan, B.; Ni, S.; Bi, Z.; Wang, Z.; Song, M. Effects of elemental segregation and scanning strategy on the mechanical properties and hot cracking of a selective laser melted FeCoCrNiMn-(N,Si) high entropy alloy. J. Alloys Compd. 2021, 865, 158892. [CrossRef]

34. Lu, Y.; Gao, X.; Jiang, L.; Chen, Z.; Wang, T.; Jie, J.; Kang, H.; Zhang, Y.; Guo, S.; Ruan, H.; et al. Directly cast bulk eutectic and near-eutectic high entropy alloys with balanced strength and ductility in a wide temperature range. Acta Mater. 2017, 124, 143-150. [CrossRef]

35. Zhang, X.K.; Chou, T.H.; Li, W.P.; Wang, Y.N.; Huang, J.C.; Cheng, L. Microstructure and mechanical properties of (FeCoNi)100-x(NiAl)x eutectic multi-principal element alloys. J. Alloys Compd. 2021, 862, 158349. [CrossRef]

36. Reverte, E.; Gordo, M.; Campos, M.; Calvo-Dahlborg, U.; Dahlborg, J.; Cornide, E. Design and Production of Novel FeCo$\mathrm{NiCrAlCu}$ High Entropy Alloy. In Proceedings of the VII Congreso Español de Pulvimetalurgia y II Congreso Iberoamericano de Pulvimetalurgia, Madrid, Spain, 24-26 June 2019.

37. Ma, Y.; Wang, Q.; Jiang, B.; Li, C.; Hao, J.; Li, X.; Dong, C.; Nieh, T. Controlled formation of coherent cuboidal nanoprecipitates in body-centered cubic high-entropy alloys based on Al2(Ni,Co,Fe,Cr)14 compositions. Acta Mater. 2018, 147, 213-225. [CrossRef]

38. Fang, P.; Xu, Y.; Li, X.; Chen, Y. Influence of Atomizing Gas and Cooling Rate on Solidification Characterization of Nickel-based Superalloy Powders. Xiyou Jinshu Cailiao Yu Gongcheng/Rare Met. Mater. Eng. 2018, 47, 423-430.

39. Praveen, S.; Murty, B.S.; Kottada, R.S. Phase Evolution and Densification Behavior of Nanocrystalline Multicomponent High Entropy Alloys During Spark Plasma Sintering. JOM 2013, 65, 1797-1804. [CrossRef]

40. Zheng, H.; Chen, R.; Qin, G.; Li, X.; Su, Y.; Ding, H.; Guo, J.; Fu, H. Microstructure evolution, Cu segregation and tensile properties of $\mathrm{CoCrFeNiCu}$ high entropy alloy during directional solidification. J. Mater. Sci. Technol. 2020, 38, 19-27. [CrossRef]

41. Monchoux, J.-P. Sintering Mechanisms of Metals Under Electric Currents. Spark Plasma Sinter. Mater. 2019, 978, 93-115.

42. Xu, X.; Guo, S.; Nieh, T.; Liu, C.; Hirata, A.; Chen, M. Effects of mixing enthalpy and cooling rate on phase formation of AlxCoCrCuFeNi high-entropy alloys. Materialia 2019, 6, 100292. [CrossRef]

43. Manzoor, A.; Pandey, S.; Chakraborty, D.; Phillpot, S.R.; Aidhy, D.S. Entropy contributions to phase stability in binary random solid solutions. NPJ Comput. Mater. 2018, 4, 47. [CrossRef]

44. Takeuchi, A.; Inoue, A. Classification of Bulk Metallic Glasses by Atomic Size Difference, Heat of Mixing and Period of Constituent Elements and Its Application to Characterization of the Main Alloying Element. Mater. Trans. 2005, 46, 2817-2829. [CrossRef]

45. Otto, F.; Yang, Y.; Bei, H.; George, E. Relative effects of enthalpy and entropy on the phase stability of equiatomic high-entropy alloys. Acta Mater. 2013, 61, 2628-2638. [CrossRef]

46. Yeh, J.-W. Recent progress in high-entropy alloys. Eur. J. Control. 2006, 31, 633-648. [CrossRef]

47. Matusiak, K.; Berent, K.; Marciszko, M.; Cieslak, J. The experimental and theoretical study on influence of $\mathrm{Al}$ and $\mathrm{Cu}$ contents on phase abundance changes in AlxCuyFeCrNiCo HEA system. J. Alloys Compd. 2019, 790, 837-846. [CrossRef]

48. Ma, Y.; Jiang, B.; Li, C.; Wang, Q.; Dong, C.; Liaw, P.K.; Xu, F.; Sun, L. The BCC/B2 Morphologies in AlxNiCoFeCr High-Entropy Alloys. Metals 2017, 7, 57. [CrossRef] 
49. Ogura, M.; Fukushima, T.; Zeller, R.; Dederichs, P.H. Structure of the high-entropy alloy AlxCrFeCoNi: Fcc versus bcc. J. Alloys Compd. 2017, 715, 454-459. [CrossRef]

50. Li, J.; Li, Z.; Wang, Q.; Dong, C.; Liaw, P. Phase-field simulation of coherent BCC/B2 microstructures in high entropy alloys. Acta Mater. 2020, 197, 10-19. [CrossRef] 